\title{
ELEMENTOS PARA UMA CRÍTICA À CONCEPÇÃO DE ANÁLISE CONCEITUAL DE RONALD DWORKIN EM JUSTICE FOR HEDGEHOGS
}

ELEMENTS FOR A CRITIQUE OF RONALD DWORKIN'S CONCEPTION OF CONCEPTUAL ANALYSIS IN JUSTICE FOR HEDGEHOGS

ELEMENTOS PARA UNA CRÍTICA A LA CONCEPCIÓN DEL ANÁLISIS CONCEPTUAL DE RONALD DWORKIN EN JUSTICE FOR HEDGEHOGS

Cecilia Caballero Lois ${ }^{1}$ Danilo dos Santos Almeida² Luiz Henrique Urquhart Cademartori ${ }^{3}$

Resumo: Em Justice for Hedgehogs, R. Dworkin sustenta as teses da unidade do valor e da dicotomia fato/valor, delimitando a moralidade como um domínio epistemológico autônomo. Consequentemente, a abordagem positivista deve ser rejeitada no que concerne à moralidade. Para ele, como o conceito de direto cumpre uma

1 Doutora em Direito pela UFSC e Professora no Curso de Direito na Universidade Federal do Rio de Janeiro. Coordenadora do PROCAD UFSC/UNIVALI/UNICAP. E-mail: cecilialois@gmail.com.

2 Mestre em Direito pela UFSC e Doutorando em Direito pela Pontifícia Universidade Católica do Rio de Janeiro. E-mail: danilodsa@gmail.com.

3 Mestre em Instituições Jurídico-políticas e Doutor em Direito do Estado pela Universidade Federal de Santa Catarina - UFSC; tem Pós-Doutorado em Filosofia do Direito pela Universidade de Granada - Espanha, é professor da Universidade Federal de Santa Catarina nos cursos de Graduação, Mestrado e Doutorado- UFSC e diversos cursos de especialização no Brasil; consultor do INEP e SESu - MEC para avaliação de cursos de direito no território nacional; foi assessor jurídico do CECCON - Centro de Controle de Constitucionalidade da Procuradoria de Justiça de Santa Catarina; autor de várias obras jurídicas e artigos sobre Direito Público. 
função de justificação de determinadas práticas sociais, ele pertence ao campo da moralidade. Portanto, sua análise não pode ser moralmente neutra. O presente trabalho sustenta que Dworkin falha ao não reconhecer que nem toda valoração tem implicações morais, ainda que ele esteja certo ao afirmar que o entendimento de um conceito valorativo é produto de uma intepretação construtiva. $A$ partir do realismo pragmático de $\mathrm{H}$. Putnam, pretende-se recorrer à ciência como exemplo de uma atividade valorativamente carregada, mas moralmente neutra. Conclui-se que é possível a coexistência de um conceito positivo e outro normativo de direito, cada um demandando uma abordagem teórica própria.

Palavras-chaves: Teoria do Direito. Justice for Hedgehogs. Realismo Interno.

Abstract: In Justice for Hedgehogs, R. Dworkin sustains the theories of unity of value and the fact/value dichotomy, construing morality as an autonomous epistemological domain. Consequently, the positivist approach should be rejected with respect to morality. For Dworkin, as the concept of law performs a justificatory function of certain social practices, it belongs to the realm of morality. Therefore, its analysis cannot be morally neutral. This paper argues that Dworkin fails to recognize that not every evaluation has moral implications, even if he is correct in stating that the understanding of an evaluative concept is the product of a constructive Interpretation. Based on the pragmatic realism of $\mathrm{H}$. Putnam, this paper looks to science as an example of a value-laden but morally neutral activity. It concludes that the coexistence of a positive and a normative concept of law is possible, each demanding a peculiar theoretical approach.

Keywords: Legal Theory. Justice for Hedgehogs. Internal Realism. 
Resumen: En Justice for Hedgehogs, R. Dworkin mantiene las tesis de la unidad de valor y de la dicotomía hecho-valor, delimitando la moralidad como un dominio epistemológico autónomo. En consecuencia, el abordaje positivista debe ser rechazado en lo que concierne a la moralidad. Para el mismo, como el concepto de Derecho cumple una función de justificación de determinadas prácticas sociales, pertenece al campo de la moralidad y por lo tanto su análisis no puede ser moralmente neutro. El presente trabajo sostiene que Dworkin falla al no reconocer que no toda valoración tiene implicaciones morales, aunque esté correcto al afirmar que el entendimiento de un concepto valorativo es producto de una interpretación constructiva. A partir del realismo pragmático de $\mathrm{H}$. Putnam se quiere recurrir a la ciencia como ejemplo de una actividad valorativamente cargada, pero moralmente neutra. Se concluye que es posible la coexistencia de un concepto positivo y otro normativo de Derecho, cada uno de ellos demandando un abordaje teórico propio.

Palabras clave: Teoría del Derecho. Justice for Hedgehogs. Realismo Interno.

\section{INTRODUÇÃO}

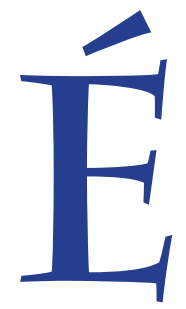

passado um bom tempo desde o auge do positivismo jurídico e, depois de décadas de provocações de ordem metodológica, ainda não se tem muita clareza do que significa produzir conhecimento jurídico. A incerteza e a insegurança são sentimentos recorrentes de quem se dedica a estudar teoria contemporânea do direito. Talvez essa seja uma consequência inevitável dos arranjos político-jurídicos do chamado neoconstitucionalismo, ou, por outro lado, talvez este seja um momento de hiato entre dois paradigmas bem estabelecidos.

O fato é que as discussões parecem cada vez mais profundas e a possibilidade de consenso, cada vez mais remota. Em situações como essa, é natural que o teórico tente aprofundar o debate e revirar o fundo das teorias em busca de um terreno sólido para fundamentar suas certezas. 
Muito tempo depois de seus primeiros lances nos debates na teoria jurídica norte-americana, Dworkin publicou, em 2011, uma formulação completa e aprofundada de seu argumento contra o positivismo, lançando raízes profundas na filosofia moral. O volumoso Justice for Hedgehogs dedica apenas quinze páginas ao problema à análise do conceito de direito, justamente o tema que o colocou junto aos grandes filósofos do direito do século XX. O novo trabalho de Dworkin reúne todas as teses que ele sustentou nos diversos aspectos do pensamento moral ao longo de sua carreira, relacionando-as sob um pequeno conjunto de proposições axiomáticas ${ }^{4}$.

Não por acaso, o conceito de direito é objeto do último capítulo. A envolvente retórica do autor faz com que, 400 páginas depois do início, mesmo suas considerações mais controvertidas sobre o direito pareçam evidentes e triviais. Uma reflexão detida de seus pressupostos, porém, indica cautela quanto às suas conclusões.

O final da obra, o último grande trabalho que Dworkin publicou antes de falecer discorre longamente sobre os principais aspectos de sua filosofia normativa, reafirma sua tese mais controversa: a de que o positivismo jurídico carece de sentido. Como é possível que gerações de filósofos do direito estivessem enganadas sobre a natureza de seu objeto de estudo? O argumento de Dworkin parte de premissas relativamente simples e alcança uma conclusão bastante severa. O presente trabalho é motivado por esse problema teórico.

A hipótese é a de que o argumento de Dworkin sobre a natureza do conceito de direito não é capaz de demonstrar a incoerência de uma teoria positivista do direito, mas apenas indicar que existe um conceito de direito para o qual não é cabível uma investigação positivista. Se a noção de conceitos interpretativos, uma das premissas de seu argumento, estiver correta, ela abrange outros tipos importantes de conceitos. Em especial, são interpretativos diversos conceitos que

$4 \quad \mathrm{Na}$ verdade, Dworkin não admite que aquelas proposições que ele próprio coloca como premissa do argumento - a tese da unidade dos valores, por exemplo - possa ter qualquer prevalência em relação às demais teses substantivas. A moralidade opera de acordo com uma epistemologia integrada, segundo a qual não existem proposições fundamentais, mas apenas a enunciação de ideias que, em última instância, só podem contar com a capacidade de produzir convencimento. Em suas próprias palavras: "In the beginning and in the end is the conviction. The struggle for integrity lies in between". (DWORKIN, Ronald. Justice for Hedgehogs. Cambridge, EUA: Harvard U. Press, 2011, p. 82 e ss). 
designam valores epistêmicos e que exercem um papel central na escolha entre paradigmas. É possível, com fundamento em tais valores, defender a superioridade de uma teoria positivista do direito. Portanto, a plausibilidade de uma tal teoria decorre da própria teoria dos conceitos de Dworkin.

A proposta do presente trabalho é levantar dúvidas sobre a curiosa tese de Dworkin de que o positivismo jurídico carece de sentido. Primeiramente, apresenta-se a crítica de Dworkin aos pressupostos metodológicos do positivismo jurídico e, logo em seguida, a proposta alternativa de Dworkin para a teoria do direito, o interpretativismo.

Posteriormente, são apresentadas algumas considerações inspiradas nos trabalhos do filósofo Hilary Putnam sobre uma das premissas de Dworkin, a de que fato e valor são aspectos logicamente distintos da experiência. Para ilustrar o argumento, recorrese ao caso dos valores epistêmicos como evidência de que atividades valorativas constituem todo tipo de empreendimento intelectual, inclusive as ciências.

Por fim e retornando ao debate jurídico, avalia-se como a revisão dos pressupostos afeta as conclusões de Dworkin acerca do conceito de direito. $O$ trabalho conclui afirmando que aquilo que Dworkin apresenta como evidência do conteúdo valorativo do conceito de direito não passa da manifestação de valores epistêmicos na teoria do direito, fato do qual nenhuma ciência está imune.

Não que Dworkin esteja errado em propor um método para a análise de um conceito normativo de direito. Desde que se admita que o conceito de direito possa cumprir um papel de justificação de determinadas práticas sociais - o reconhecimento de direitos ou o exercício da força coerciva, por exemplo -, então o interpretativismo é a abordagem adequada. Mas isso não significa que não possa haver um conceito de direito cuja função seja meramente descritiva. Nesse caso, o positivismo impõe-se como modelo mais adequado para a teoria do direito.

O método aqui utilizado é o indutivo, pois o que se pretende é por à prova o argumento de Dworkin, investigando alguma de suas consequências não explorada pelo próprio autor. A técnica de pesquisa adotada é a da pesquisa bibliográfica.

Antes de iniciar o desenvolvimento do trabalho, algumas definições precisam ser acordadas. Interpretativismo é teoria em que direitos e deveres jurídicos de 
uma dada comunidade política são determinados pela interpretação de suas práticas e valores que fornece a sua melhor justificação ${ }^{5}$. Por epistemologia integrada, designa-se a posição segundo a qual as crenças em um domínio do conhecimento humano devem estar em harmonia entre si e que, nesse domínio, qualquer critério de validade das proposições deve ser, ele mesmo, uma proposição da mesma ordem e com o mesmo estatuto 6 . A noção de arquimedianismo pode ser definida em contradição com essa última, como a tentativa de estabelecer como critério de validade proposições externas ao domínio em questão7.

Por fim, conceitos de valores epistêmicos são aqueles, tais como o de coerência e de simplicidade, que guiam a escolha por teorias nas ciências e em outros domínios ${ }^{8}$.

\section{A CRÍTICA METODOLÓGICA DE DWORKIN AO POSITIVISMO} JURÍDICO ANALÍTICO

Dworkin fez seu nome como intelectual público com uma série de ataques à concepção de direito corrente no mundo anglo-saxão. Seu alvo preferido foi naturalmente o maior filósofo do direito anglófono do século XX, Herbert Hart.

As críticas de Dworkin ao modelo de positivismo do professor britânico abrangem uma grande variedade de assuntos. Algumas delas de fato levaram Hart a reconsiderar aspectos relevantes de sua teoria ${ }^{9}$. Mas uma delas continuou sendo tema de debates por décadas, tendo ocupado grande parte do pós-escrito

5 STAVROPOULOS, Nicos. Interpretivist Theories of Law. In: VILLANUEVA, Enrique (org.). Law: metaphysics, meaning and objectivity. Nova Iorque, EUA: Rodopi, 2007, p. 3.

6 DWORKIN, Ronald. Justice for Hedgehogs. p. 82.

7 DWORKIN, Ronald. Justice for Hedgehogs. p. 25.

8 PUTNAM, Hilary. Realism with a Human Face. Cambridge, EUA: Harvard U. Press, 1990, p. 138.

9 Hart reconhece que Dworkin estava certo quanto à importância que a ideia de princípios jurídicos pode ter em alguns sistemas jurídicos. Uma falha de The Concept of Law é de não ter desenvolvido o tópico da decisão judicial e, portanto, de não ter apreendido elementos típicos da argumentação jurídica (HART, Herbert. Pós-escrito. In: o Conceito de Direito. Tradução de Antônio O. Sette-Câmara. São Paulo: WMF Martins Fontes, 2009, p. 335). A resposta de Hart é que, ainda que seu livro não tenha estudado satisfatoriamente a prática da argumentação em sede de decisão judicial, não é justa a acusação de ter desconsiderado a existência de normas jurídicas "não conclusivas", tal como os princípios. Normas que, em maior ou menor grau, conflitem com outras no caso concreto podem depender da articulação de padrões jurídicos variáveis, e isso não entra em conflito com as teses centrais do positivismo jurídico. (HART, Herbert. Pós-escrito. p. 339). 
que redigiu para o seu The Concept of Law. Justice for Hedgehogs certamente está destinado a reavivar a discussão. O tema em questão é a natureza da análise conceitual na teoria do direito.

Dworkin nega que Hart seja capaz de fazer jus à essência do conceito de direito ao tratá-lo como simples fato ${ }^{10}$. Nenhuma concepção de direito que parta de uma perspectiva externa ${ }^{11}$, tal como a proposta de uma teoria descritiva de Hart, poderia explicar de que forma as contendas sobre o que constitui o direito compõem exatamente o que é esse mesmo direito. As teorias do direito como simples fato falham, segundo o autor, pois não levam em conta o papel das considerações morais na argumentação jurídica e sustentam uma semântica criterial para significação dos conceitos jurídicos, como o próprio conceito de direito.

Isso reflete na teoria do direito. Para Dworkin, não existe uma disciplina que esteja fora da linguagem jurídica e que seja capaz de esclarecer o que o direito é para seus participantes ${ }^{12}$. Distinguir níveis de discurso valorativo e meramente descritivo - significado de um conceito e sua explicação - é fazer epistemologia arquimediana. O direito - assim como a justiça, a liberdade, a democracia - é um conceito interpretativo.

O direito não é um simples fato social e qualquer concepção de interesse jurídico - e não meramente sociológico ou histórico - deve dar conta de seu caráter valorativo. Uma concepção meramente descritiva comete o erro de confundir conceitos criteriais com conceitos interpretativos ${ }^{13}$. Conceitos políticos, 10 DWORKIN, Ronald. O Império do Direito. 2. ed. Tradução de Jefferson L. Camargo. São Paulo: Martins Fontes, 2007, pp. 10-15 e 30-38.

11 Por perspectiva externa, Dworkin refere-se a uma concepção de direito que não esteja engajada em disputas jurídicas doutrinárias. Portanto, ela é externa em relação a problemas localizados de sistemas jurídicos específicos.

12 DWORKIN, Ronad. Justice in Robes. Cambridge, EUA: Harvard U. Press, 2006, p. 140-141.

13 Dworkin chama de criteriais os conceitos sobre os quais é possível enunciar critérios de correção para seu uso. Por exemplo, o conceito de solteiro só faz sentido para quem domina o conjunto de suas propriedades fundamentais. Diz-se que uma pessoa compartilha o conceito de solteiro se ela for capaz de respeitar determinadas regras relativas ao seu significado (não usá-lo para designar homens casados ou viúvos, por exemplo). É possível que haja alguma divergência sobre quais são tais regras (pode-se chamar um menino de dois anos ou um padre de solteiro?), mas ela não reflete nada de significativo. Os critérios são definidos espontaneamente em uma dada cultura (ou arbitrariamente, se o conceito for um elemento de uma linguagem formalizada), portanto, o conceito não pode ser corrigido por nada além de seus próprios critérios. É justamente isso que o distingue dos conceitos interpretativos e dos de tipos naturais (aqueles que designam entidades que possuem uma estrutura interna a ser descoberta pela ciência): não existe coisa alguma a ser descoberta 
tais como o de direito, têm um valor subjacente e estão orientados para cumprir determinada finalidade. Teorizar sobre determinado valor é atribuir-lhe um significado, fornecer uma interpretação ao mesmo tempo do que é este valor e o que ele requer ${ }^{14}$. Esta é a interpretação construtiva que Dworkin defende como método para o pensamento jurídico.

Dworkin defendeu em seu argumento do aguilhão semântico que a análise de conceitos relacionados a práticas sociais não pode oferecer uma descrição neutra de seu objeto. Olhando o histórico de sua própria bibliografia, ele reconhece ter apresentado uma concepção de direito falha em seus primeiros trabalhos. $\mathrm{Na}$ época, entendia que direito e moralidade são dois sistemas diferentes e que a tarefa da teoria do direito é medir o grau de imbricação entre eles ${ }^{15}$.

Desde então, e tendo como marco a publicação de seu livro Law's Empire, o conceito de direito passou a ser caracterizado por Dworkin como profundamente conflitivo, tal como os conceitos políticos ou morais. O que os torna tão intrinsecamente contenciosos é o fato de dependerem de uma atribuição teleológica, de valores que Ihes dão substância ${ }^{16}$. O que Justice for Hedgehogs tem de novo a oferecer para a compreensão da teoria do direito é que, dada a unidade dos valores, não há uma distinção clara entre direito e moral. Ambos são parte do mesmo tipo de atividade intelectual e distinguem-se somente pelo propósito a que servem ${ }^{17}$.

Para Dworkin, o trabalho do teórico do direito é promover a análise do conceito de direito, ou seja, dizer qual é seu significado elucidando seus componentes fundamentais. O direito não tem uma estrutura profunda que possa ser descoberta por uma investigação empírica. A divergência dos profissionais do direito acerca de suas proposições fundamentais indica que ele também não é um conceito meramente convencional; portanto, não há critérios de uso definidos que possam ser esclarecidos pelo teórico.

a seu respeito além dos próprios critérios de uso e correção. Sobre as classes de conceitos descritas por Dworkin, ver DWORKIN, Ronald. Justice for Hedgehogs. p. 158-170.

14 DWORKIN, Ronald. O Império do Direito. pp. 57-58; DWORKIN, Ronald. Justice in robes. p. 12.

15 DWORKIN, Ronald. Justice for Hedgehogs. pp. 404-405.

16 DWORKIN, Ronald. Justice in robes. p. 149.

17 DWORKIN, Ronald. Justice for Hedgehogs. p. 405. 
O que existem são diferentes concepções, que reconstroem a prática do direito atribuindo importância a diferentes elementos tidos como essenciais. Assim, a atribuição de sentido ao direito depende do valor que lhe é atribuído em cada diferente concepção. Dada a ideia de epistemologia integrada - que decorre do princípio da dicotomia fato/valor - presente na filosofia moral de Dworkin, a análise de conceitos valorativos não é diferente da justificação de teorias substantivas.

Assim, não é possível propor uma teoria do direito neutra em relação a seu objeto. O critério que orienta o teórico a privilegiar alguns elementos da prática em detrimento de outros é valorativo e tem a mesma natureza do critério que leva o juiz a sustentar uma determinada concepção do direito vigente.

\section{O MODELO INTERPRETATIVISTA DE TEORIA DO DIREITO}

Nos trabalhos de Dworkin, a ideia de interpretação tem um papel muito maior que meramente o resgate do significado dos textos ou a reconstrução da atividade judicial. Ela é também a única abordagem analítica ${ }^{18}$ que o conceito de direito comporta. Para entender essa surpreendente afirmação, é importante levar em conta seus argumentos mais recentes no âmbito da filosofia moral.

Desde Law's Empire, a teoria do direito de Dworkin ganha os contornos do que veio a ser denominado interpretativismo - o modelo segundo o qual o fato que torna as proposições jurídicas verdadeiras ou falsas é interpretativo. Desde então,

18 Um aspecto fundamental no argumento de Dworkin é que outras abordagens para o problema do significado do adjetivo "jurídico" são possíveis, e elas podem ser conduzidas segundo os mais variados métodos. O que ele sempre afirmou é que a abordagem positivista para a teoria do direito é inadequada. Grande parte da teoria do direito positivista desenvolveuse como argumento conceitual, ou seja, como análise do que está implicado na "fala sobre o direito", tanto em termos de atitudes proposicionais, quanto de fenômenos referenciados (LEITER, Brian. Naturalizing Jurisprudence: essays on American legal realism and naturalism in legal philosophy. Nova Iorque, EUA: Oxford U. Press, 2007, pp. 123-124). Segundo Dworkin, os positivistas jurídicos agem como se o conteúdo do conceito de direito pudesse ser descrito mediante a enunciação de critérios definidos. Mas isso não pode ser feito, pois integram seu conteúdo juízos valorativos, que são intrinsecamente disputados. Isso não significa que outras disciplinas não possam adotar uma abordagem positivista. Pode haver outros conceitos de direito diferentes do "conceito doutrinal de direito" que, segundo Dworkin, é aquele que é objeto da teoria do direito (DWORKIN, Ronald. Justice for Hedgehogs. p. 402). 
a fonte de normatividade do direito é a sua justificação. Isto porque, desde que começou a abandonar a ideia dos dois sistemas, Dworkin pode oferecer como alternativa à identificação de fatos políticos - as decisões de autoridades - uma teoria da moralidade pública como fonte de normatividade. Isso é o mesmo que dizer que um sistema de normas jurídicas só é racionalmente aceitável perante um sujeito que o considera justificável.

De fato, em grande parte de seu novo livro Dworkin dedica-se a esclarecer e a defender aspectos específicos de sua teoria da moralidade, tais como a ideia de conceitos interpretativos e de responsabilidade moral, que são indispensáveis para sua concepção de teoria do direito. Assim, ao ampliar o interpertativismo ao nível de uma teoria para discurso normativo em geral, Dworkin pode demonstrar que sua concepção de direito decorre de uma teoria moral abrangente.

Desta forma, o conceito de direito é tido como interpretativo, da mesma forma que os conceitos morais e políticos. A verdade das proposiçõesjurídicas específicas é determinada pelas proposições fundamentais do sistema jurídico ${ }^{19}$, eles são parâmetros seguros para identificação da solução mais adequada ao direito em cada caso. Todavia, por conta do caráter interpretativo do direito, as proposições fundamentais são profundamente contestadas. Os atributos essenciais da prática do direito estão sujeitos à reconstrução operada pela atividade interpretativa ${ }^{20}$.

Apesar de reconhecer que determinados fatos políticos - como decisões legislativas ou judiciais - são consensualmente relevantes na identificação do direito, o interpretativismo afirma que o que os torna juridicamente relevantes é o "fato normativo" de que essa é a melhor configuração para o direito ${ }^{21}$. Casos fáceis e difíceis, relativos a questões específicas ou a fundamentos do direito, todos estão sujeitos a uma crítica moralmente engajada. Assim, toda proposição jurídica deve ser coerente com uma teoria - expressa ou meramente suposta - que

19 Dworkin chama de fundamentais as proposições que indicam quais fatos constituem evidência para as proposições jurídicas em geral. Por exemplo, o que torna verdadeira a proposição de que é proibido dirigir acima de acima de $90 \mathrm{Km} / \mathrm{h}$ na Califórnia é o fato de uma lei ter sido votada em um determinado momento - ou, mais precisamente, que houve uma série de ritos conduzidos por pessoas intituladas "legisladoras" ( $\mathbf{O}$ império do direito, p. 7).

20 STAVROPOULOS, Nicos. Interpretivist Theories of Law. p. 10.

21 STAVROPOULOS, Nicos. Interpretivist Theories of Law. p. 14. 
potencialmente abranja a totalidade do direito; entendido como ordenamento jurídico específico ou como fenômeno genérico ${ }^{22}$.

Pode-se concluir que a teoria do direito está metodologicamente relacionada à filosofia moral ${ }^{23}$. Considerando que a interpretação só pode iniciar dentro de gêneros interpretativos amplamente aceitos $^{24}$, a questão sobre quais são as fronteiras entre a moral e o direito, dentro do modelo de Dworkin, não pode fazer sentido. Assim, o problema dos limites entre moral e direito - se eles devem ou não ser postulados - só pode ser resolvido da perspectiva de um dos dois sistemas normativos, pelos usos de um dos dois gêneros intepretativos ${ }^{25}$. Portanto, qualquer resposta será parcial e sujeita a objeções de ordem moral.

\section{A IMBRICAÇÃO DE VALORES NOS FATOS E O REALISMO PRAGMÁTICO DE HILARY PUTNAM}

Pode-se sintetizar o argumento da seguinte forma. Existe uma classe de conceitos que têm conteúdo valorativo e servem para justificar práticas sociais; eles são chamados de interpretativos. Como os valores são epistemologicamente autônomos e o conhecimento a seu respeito é independente de evidências sobre a realidade concreta, os conceitos interpretativos só podem ser compreendidos se estiverem consistentemente articulados em uma teoria abrangente dos valores. $O$ direito é uma prática social cuja função é garantir o conjunto de direitos jurídicos

22 STAVROPOULOS, Nicos. Interpretivist Theories of Law. p. 12

23 O direito tem outras relações com a moralidade para além da teoria do direito. Uma teoria da legislação deve dar conta de garantir que as normas jurídicas legisladas sejam justas em alguma medida (DWORKIN, Ronald. Justice for Hedgehogs. p. 401). Outra dessas relações é que uma teoria da decisão judicial pode adotar critérios morais para corrigir a legislação vigente, como nos casos de controle de constitucionalidade. Tais critérios incidiriam sobre a validade de uma determinada norma. Ou seja, dentre as proposições fundamentais do direito, pode haver aquelas mais próximas do que seria considerado típicos julgamentos morais - juízos de equidade, por exemplo. Isso não é problema para os positivistas inclusivos como Hart, os quais aceitam que determinados sistemas jurídicos tenham alguma abertura para argumentos morais (HART, Herbert. Pós-escrito. p. 335). Presumivelmente, tal abertura argumentativa para princípios morais tem reflexos para o problema mais abstrato do que pode ser considerado jurídico. Aqui interessam esses reflexos mais abstratos, relacionados à natureza do conceito de direito e que separa Dworkin dos positivistas, mesmo que inclusivos.

24 DWORKIN, Ronald. Justice for Hedgehogs. p. 134.

25 DWORKIN, Ronald. Justice for Hedgehogs. p. 402. 
(legal rights) a que cada cidadão tem direito ${ }^{26}$. Quais são os direitos jurídicos de cada um é um problema de direito constitucional relacionado a qual é o propósito ou valor ao qual o direito deve servir. Consequentemente, o conceito de direito é interpretativo e não está sujeito a uma investigação moral e doutrinariamente neutra. Logo, o positivismo jurídico não é uma alternativa disponível.

Para contrastar com as considerações metodológicas de Dworkin, este trabalho recorre aos esforços do filósofo norte-americano Hilary Putnam ${ }^{27}$ no sentido de derrubar a barreira que os epistemólogos levantaram entre noções fáticas e noções valorativas ou normativas. Durante quase três séculos - desde a publicação de $A$ Treatise of Human Nature, de David Hume - aceitou-se que tal diferença refletia uma cisão lógica insuperável e, mais do que isso, que a possibilidade de verdadeiro conhecimento a ser obtido no lado valorativo deveria ser vista com ceticismo ${ }^{28}$.

Para Putnam, era fundamental combater a distinção para garantir o estatuto epistemológico da ética, por exemplo. Dworkin parece ter tomado um caminho oposto, visando obter o mesmo resultado. Por engenhosa que seja a sua teoria, argumentar-se-á no presente trabalho que Putnam tinha razão ao desconfiar da dicotomia entre fato e valor e que a demarcação entre ciência e não ciência - ou entre ciência e interpretação, como quer Dworkin - é muito problemática.

O grande problema é que a categoria dos conceitos interpretativos é mais abrangente que Dworkin parece disposto a admitir. Por exemplo, o modelo de realismo pragmático de Putnam $^{29}$ prevê que mesmo as verdades mais

26 DWORKIN, Ronald. Justice for Hedgehogs. p. 406.

27 Hilary Putnam (1926-) é um dos expoentes da filosofia analítica nos EUA. Com notável desenvoltura, foi capaz de debater em ramos bastante diversos do conhecimento. Fez contribuições sumamente relevantes para as áreas da epistemologia, filosofia da linguagem e ética. Juntamente com Richard Rorty e Willard Quine, é tido como um dos principais herdeiros da tradição pragmatista norte-americana. Putnam foi discípulo de dois importantes representantes do positivismo lógico nos EUA - ambos alemães que migraram para os EUA com a ascensão do nazismo - Hans Reichenbach e Rudolph Carnap. Apesar disso, ele demonstrou consternação ao longo de sua carreira com a insistência desses autores em distinguir fato e convenção - esta crítica já havia sido sistematicamente feita por Quine, também professor de Putnam - e fato e valor. (CF. PUTNAM, Hilary. O Colapso da Verdade e Outros Ensaios. Tradução de Pablo R. Mariconda e Sylvia G. Garcia. Aparecida: Idéias \& Letras, 2008. pp. 179-180).

28 PUTNAM, Hilary. O Colapso da Verdade e Outros Ensaios. p. 28.

29 Putnam afirma que diversos problemas de ordem conceitual que habitam as discussões nas ciências naturais e na matemática - sobre a natureza dos números, por exemplo - refletem um fenômeno cultural que pode ser chamado de "relatividade conceitual", pelo qual deter- 
fundamentais podem ser disputadas tais como as verdades morais de Dworkin. Relatividade conceitual é a situação em que um dado esquema conceitual pode determinar afirmações rigorosamente opostas a outro esquema alternativo, sem que eles de fato estejam em contraposição - no sentido em que não é possível decidir de forma neutra, não engajada, qual delas é a mais adequada ${ }^{30}$.

Assim, como não é uma questão de fato uma dada interpretação ser verdadeira, ela também reflete um tipo de divergência significativa, tal como os conceitos interpretativos de Dworkin. Este autor entende que a divergência entre duas pessoas sobre o que é certo ou errado só pode ser indício de relativismo - a posição segundo a qual não há verdade objetiva - segundo a avaliação de uma terceira pessoa, uma intérprete do conflito apta a oferecer as suas próprias conclusões morais ${ }^{31}$. No fundo, o que é verdadeiro ou falso só pode ser compreendido no âmbito de uma determinada teoria; isso é exatamente o que o realismo de Putnam apresenta ${ }^{32}$.

Se esse for mesmo o caso, então toda a descrição está sujeita a noções fundamentais cuja atribuição de significado funcione como os conceitos interpretativos de Dworkin. Ou seja, modelos descritivos também estão fundados em divergências que não podem ser resolvidas como questões de fato ${ }^{33}$, sem que se precise supor que essas divergências tenham qualquer implicação ética ou moral. Isso significa que diferentes formas de descrever a realidade podem coexistir, ainda que sejam mutuamente incompatíveis, pelo simples fato de que os esquemas conceituais disponíveis não são suficientemente completos ao ponto de a ambiguidade estar completamente excluída ${ }^{34}$.

De volta às divergências conceituais no direito, o problema da natureza do direito pode ser abordado como uma construção doutrinária, interna ao discurso minados objetos abstratos, que dos quais determinados modelos teóricos são fundados, podem ou não existir, dependendo do esquema conceitual adotado (Cf. PUTNAM, Hilary. Ethics Without Ontology. Cambridge, EUA: Harvard University Press, 2004. pp. 39-40). Para Putnam, a teoria segundo a qual se pode adotar uma posição ou outra, dependendo do propósito em questão, é o que se chama "realismo interno" (Ethics Without Ontology. p. 35), ou ainda, "realismo pragmático" (Ethics Without Ontology. p. 17).

30 PUTNAM, Hilary. The Many Faces of Realism: the Paul Carus lectures. Lasalle, EUA: Open Court, 1987, p. 19.

31 DWORKIN, Ronald. Justice for Hedgehogs. p. 121.

32 PUTNAM, Hilary. Realism with a Human Face. p. 96.

33 PUTNAM, Hilary. Ethics Without Ontology. p. 47.

34 PUTNAM, Hilary. Ethics Without Ontology. p.43. 
jurídico, mas pode também ser visto de um ponto de vista teórico. O primeiro caso, que pode ser denominado conceito normativo de direito ${ }^{35}$, é o adequado para se formular uma justificação para determinada concepção de direito.

Isso porque, da perspectiva interna de um participante e em um ordenamento jurídico que não seja simplesmente um sistema de regras, o que define a obrigatoriedade de uma norma ${ }^{36}$ - o que distingue uma norma aceitável de uma norma "errada"37 - é uma teoria abrangente que dê conta dos propósitos a que servem o direito. No fundo, uma teoria do direito que seja um caso especial de uma teoria da moralidade pública ${ }^{38}$. A melhor forma de se buscar uma solução para o problema não é dada criterialmente pelo próprio conceito.

O que o interpretativista pode almejar é oferecer uma concepção de direito que seja adequada à forma como os participantes, no âmbito de seus ordenamentos jurídicos específicos, encaram o discurso jurídico. Essa abordagem é semelhante ao positivismo no sentido em que tenta "explicar"39 como opera o discurso do direito, ainda que interpretativamente, apontando elementos que estão subjacentes ${ }^{40}$.

Dworkin falha em sua caracterização da função do teórico. Ele sustenta que o direito é dotado de um propósito e só se pode entendê-lo a partir de uma caracterização favorável das práticas jurídicas à luz desse propósito. Essa é uma tarefa moralmente engajada, pois é preciso justificar o direito enunciando sua finalidade. O que Dworkin não pode esperar é que todo o teórico do direito concorde, sem mais, com esse conceito normativo de direito; o seu não é necessariamente $o$ conceito de direito ${ }^{41}$.

Dworkin propõe uma releitura interpretativista do positivismo jurídico, denominado convencionalismo ou, em Justice for Hedgehogs, "imagem dos dois

35 LEITER, Brian. Naturalizing Jurisprudence. p. 165.

36 DWORKIN, Ronald. Justice for Hedgehogs. p. 408.

37 DWORKIN, Ronald. Justice for Hedgehogs. pp. 410-411.

38 SOLUM, Lawrence, The Unity of Interpretation. Boston University Law Review, v. 90, n. 2, pp. 551-578, abr. 2010. p. 557.

39 Esta palavra está entre aspas para não haver confusão com o sentido que Dworkin atribui. Como já foi dito, para ele, explicação é algo que não cabe no âmbito de uma teoria normativa. No sentido em que está colocado aqui, nada impede que o interpretativismo seja uma explicação - ou abranja uma função explicativa - do fenômeno jurídico.

40 LEITER, Brian. Naturalizing Jurisprudence. p. 140.

41 LEITER, Brian. Naturalizing Jurisprudence. p. 166. 
sistemas" (two-systems picture) ${ }^{42}$. Ela decorreria de uma interpretação do direito no qual nenhuma consideração moral deve é admitida ${ }^{43}$. Este modelo refletiria as posições mais substanciais do positivismo jurídico sem suas premissas metodológicas. Essa releitura interpretativa da compreensão que o positivismo tem do direito não contribui para seu argumento teórico, porque supõe que alguém que pense um direito livre de argumentos morais ainda esteja vinculado a uma abordagem interpretativa.

Assim, considerando o fato de o conceito de direito não impor uma abordagem interpretativa, pode-se aceitar que a sua compreensão se dê de duas formas diferentes. Se a teoria do direito for entendida como ciência, em vez de como filosofia do direito (jurisprudence), ela cria um nível intermediário entre a concepção de análise conceitual proposta por Dworkin e as ciências que se colocam de uma perspectiva completamente externa, de observador.

Essa distinção é estranha ao pensamento de Dworkin. Nesse segundo sentido, teoria do direito deve indicar um modelo teórico intermediário entre uma teoria normativa e uma ciência puramente empírica ${ }^{44}$. Ela dedica-se a enunciar padrões de comportamento mais ou menos seguros para a identificação da prática do direito $45 / 46$.

Diferentemente das teorias normativas, tais como o interpretativismo, essa ciência do direito não se posiciona quanto a melhor solução para os problemas jurídicos - ela é neutra - e não depende de características próprias de sistemas jurídicos específicos - ela é geral. E ela propõe uma descrição de como indivíduos submetidos ao controle regulatório de um conjunto de normas, em oposição às

42 DWORKIN, Ronald. Justice for Hedgehogs. p. 402.

43 DWORKIN, Ronald. Justice for Hedgehogs. p. 409.

44 PERRY, Stephen. Hart's Methodological Positivism. In. COLEMAN, Jules (ed.) Hart's Postscript: essays on the Postscript to the Concept of Law. Nova Iorque, EUA: Oxford U. Press, 2001. pp. 325-326.

45 HART, Herbert. Pós-escrito. p. 325.

46 O quanto de segurança que uma tal teoria pode pretender é um aspecto importante do argumento de Dworkin contra o caráter científico da teoria do direito. Sua objeção - principalmente tal como foi formulada em Law's Empire (DWORKIN, Ronald. Império do Direito. pp. 19-38) - é que a natureza do conceito de direito é tal que não há padrões publicamente compartilhados a serem enunciados. Para Hart, existe espaço na teoria para os princípios que orientam a tomada de decisão e a incerteza que eles ensejam na descrição de critérios públicos - na incerteza marginal que denominou de penumbra (Cf. HART, Herbert. Pós-escrito. p. 325). 
ciências empíricas que forneceriam explicações que excluiriam estados mentais e atitudes dos participantes ${ }^{47}$.

É claro que Dworkin rejeita essa instância intermediária. Para ele, uma teoria que pretenda levar em consideração o aspecto normativo de uma prática social deve fazê-lo, ela mesma, por meio de compromissos normativos. Isso ocorre pelo fato de os valores estarem vinculados a uma epistemologia integrada, que os une em uma mesma teoria abrangente ${ }^{48}$, e pelo caráter interpretativo dos conceitos de valor, que impõe os parâmetros do próprio gênero interpretativo ${ }^{49}$.

\section{VALORES EPISTÊMICOS COMO EXEMPLO DA IMBRICAÇÃO}

Um ponto fundamental, mas pouco explorado, diz respeito à concepção de valor de Dworkin. Ele afirma a tese da unidade, pelo menos, dos valores éticos e morais ${ }^{50}$. Consequentemente, um dos critérios de verdade no domínio dos juízos de valor é a coerência com o conjunto de juízos morais e éticos que um sujeito sustenta com convicção. O problema é que existem também valores epistêmicos, que regulam a produção de qualquer forma de conhecimento. Dworkin não afirma se a tese da unidade dos valores abrange os valores epistêmicos.

Na verdade, ele dedica muito pouca atenção ao problema, afirmando que ele é "exagerado"51 e que ele não afeta o problema da justificação da prática da ciência ${ }^{52}$. As colocações de Dworkin a respeito denotam uma excessiva simplificação e desmerecimento da importância dos aspectos não descritivos da ciência, tais como os relacionados à construção de modelos analógicos ou ideais, a disputa entre paradigmas em momentos de ciência revolucionária, a definição dos conceitos fundamentais de uma teoria, entre outros.

O exemplo dos valores epistêmicos tem a dupla função de crítica da ideia de que existe algo com um método de investigação que seja imune aos juízos de valor e como um argumento pela objetividade de disciplinas como a moral. A 47 PERRY, Stephen. Hart's Methodological Positivism. pp. 325-326 e 328.

48 DWORKIN, Ronald. Justice for Hedgehogs. p. 101.

49 DWORKIN, Ronald. Justice for Hedgehogs. pp. 124-125.

50 DWORKIN, Ronald. Justice for Hedgehogs. p. 1.

51 DWORKIN, Ronald. Justice for Hedgehogs. p. 430, nota 6.

52 DWORKIN, Ronald. Justice for Hedgehogs. p. 453, nota 48. 
questão é que a distinção entre a ciência dos fatos brutos e a interpretação da moral não leva em conta que a natureza dos chamados valores epistêmicos - aqueles que auxiliam a obtenção de teorias verdadeiras - é a mesma dos valores morais.

Isso significa que, muitas vezes, os modelos científicos precisam recorrer à mesma justificação autorreferente dos conceitos éticos espessos ${ }^{53}$; assim como a ideia de cruel só pode ser explicada com termos semelhantes, o mesmo vale para o conceito de confirmação. A força normativa das práticas que integram o método científico só é compreensível da perspectiva do agente e pressupõe uma noção de racionalidade como "fato que implica um dever" (ought-implying fact) ${ }^{54}$.

A distinção entre ciência e interpretação não se sustenta, primeiramente, porque grandes partes da atividade científica, principalmente na época em que um paradigma é substituído por outro, são orientadas pela definição de propósitos. Em segundo lugar, a própria atividade interpretativa implica, assim como na ciência, na fixação deferencial do significado de seus conceitos.

Nos períodos de substituição de paradigmas, momento da chama ciência revolucionária, antes que qualquer das novas teorias à disposição possa ser confirmada, os julgamentos teóricos são feitos segundo os critérios de simplicidade, consiliência e conservadorismo.

Ou seja, as antecipações de um possível novo paradigma dependem de um tipo especial de juízo de valor, umjuízo sobre valores epistêmicos. Putnam menciona o exemplo ilustrativo da teoria einsteiniana da gravitação que foi incorporada pela comunidade científica cinquenta anos antes da desconfirmação da alternativa disponível ${ }^{55}$. O exemplo indica que a separação entre juízos de fato e juízos de valor não é tão funcional assim.

\section{DOIS CONCEITOS DE DIREITO}

Dworkin sustenta que as teses da dicotomia entre fato e valor e da unidade dos valores têm implicações metodológicas, sem aceitar que possa haver 53 São chamados de espessos os conceitos éticos que têm, também, uma forte carga descritiva. Um exemplo é o conceito de crueldade.

54 PUTNAM, Hilary. Pragmatism and Moral Objectivity. In: Words and Life. Cambridge, EUA: Harvard U. Press, 1994. p. 168.

55 PUTNAM, Hilary. Realism with a Human Face. p. 138. 
compatibilidade entre o caráter valorativo do objeto e a neutralidade moral do modelo explicativo.

Toda a delimitação de um campo de estudo implica alguma forma de valoração, mas isso não significa que a teoria adequada tenha que ser ela mesma valorativa. O julgamento feito pelo teórico dos elementos importantes e significativos de uma prática social tem algum caráter valorativo, que não significa que seja necessariamente um exemplo de julgamento moral. O que Dworkin entende por reflexos morais da teoria do direito, derivados de um argumento do holismo dos valores, deve ser entendido como o tipo de atividade interpretativa comum a qualquer forma de descrição.

Pode-se ir além afirmando que esse será o caso ainda que a prática social em questão seja reconhecida por seus participantes como uma atividade moralmente engajada ${ }^{56}$. Em se tratando de análise conceitual, o que define a postura mais adequada ao investigador é a natureza do seu objeto, que é um determinado conceito. Para isso, importa pouco se tal conceito remete ou não a uma atividade reflexiva.

O que interessa são os atributos do próprio conceito, por exemplo, o que é tido como seu sinônimo, quais são suas instâncias paradigmáticas e a que propósito ele serve nos contextos em que eles são utilizados ${ }^{57}$. Um conceito será ele próprio valorativo e sujeito a considerações de ordem moral se cumprir a função de justificar uma determinada atividade.

O conceito de liberdade, por exemplo, cumpre a função de designar algo de essencialmente bom segundo parâmetros a serem estabelecidos. Ao mesmo tempo em que é correto dizer que gozar de liberdade em geral é algo valioso, pode-se dizer que não existe critério consensual para definir exatamente o que significa gozar de liberdade. Métodos como levantamento estatístico de seus usos comuns dificilmente poderiam ajudar a clarear seu significado.

56 LEITER, Brian. Naturalizing Jurisprudence. pp. 165-168.

57 Leiter vale-se de uma analogia da teoria do direito como o que poderia ser chamado de "teoria da cidade". Ele demonstra que, assim como para o conceito de cidade, a análise do conceito de direito demanda determinados compromissos metodológicos que dizem respeito não ao seu objeto, mas aos seus atributos. Por exemplo, ambos os conceitos permitem uma indicação estatística de seus usos mais comuns (LEITER, Brian. Naturalizing Jurisprudence. pp. 168-170). 
Foi dito que a questão metodológica contra o positivismo está no caráter interpretativo da noção de direito. A possibilidade de uma teoria neutra do direito baseia-se no fato de que a análise de um conceito significa a sua explicação. $O$ que se espera de alguém que tenha compreendido um determinado conceito é que ele seja capaz de explicar suas características principais ${ }^{58}$. É verdade que, para determinar quais são as características que realmente importam para a compreensão de um conceito, alguma forma de avaliação é indispensável ${ }^{59}$. Mas o juízo de valor pertinente aqui não é o mesmo a que Dworkin se refere.

Para Brian Leiter, o conceito normativo de direito pode ser aceito se for demonstradoseramelhorexplicaçãodoconceitoqueefetivamenteécompartilhado por uma dada comunidade ${ }^{60}$. Nesse caso, a comunidade que interessa é a de teóricos do direito ${ }^{61}$. Os únicos aspectos normativos envolvidos na explicação do conceito é a determinação de quais são os seus elementos característicos e quais são acidentais. Esse tipo de normatividade é comum a toda investigação científica, significa a exigência de respeito aos valores epistêmicos ${ }^{62}$.

Toda a investigação exige alguma escolha acerca de como sistematizar os dados disponíveis; determinados casos, em especial os casos limítrofes, exigem uma ponderação ${ }^{63}$. Não há razões para se pensar que o caráter interpretativo ou discursivo de determinada prática interfira nas decisões metodológicas necessárias

58 RAZ, Joseph. Two Views of the Nature of the Theory of Law: a partial comparison. In: COLEMAN, Jules (ed.) Hart's Postscript: essays on the Postscript to the Concept of Law. Nova Iorque, EUA: Oxford U. Press, 2001, p. 8.

59 LEITER, Brian. Naturalizing Jurisprudence. p. 167.

60 LEITER, Brian. Naturalizing Jurisprudence. p. 166.

61 Esse é outro ponto delicado. A quem pertence o conceito de direito? Para Dworkin, o conceito de direito é moralizado porque os profissionais do direito o tratam assim. É nisso que ele fundamenta seu argumento do aguilhão semântico em Law's Empire (DWORKIN, Ronald. Império do Direito, pp. 19 e ss). Porém, quando ele se refere ao problema do direito injusto, fica claro que os juízes frequentemente confundem-se, tratando-o como se fosse direito válido, mas imoral (DWORKIN, Ronald. Justice for Hedgehogs, pp. 410-412). Dworkin pode dizer que os juízes usam o conceito de direito como um conceito interpretativo, mas não pode dizer que eles são conscientes disso; só ele próprio e os interpretativistas o são. Assim, só os teóricos do direito conhecem o conceito de direito - entendem-no suficientemente bem para corrigir seu uso; os juristas não passam de usuários leigos.

62 LEITER, Brian. Naturalizing Jurisprudence. p. 168.

63 O exemplo de Leiter do conceito de cidade é ilustrativo. Não há na prática de se morar em cidades a normatividade que Dworkin identifica no direito, dada a sua proximidade com a moral. Ainda assim, determinar quais são os critérios para se identificar uma cidade pode ser bastante disputado e defini-los pode exigir julgamentos práticos (LEITER, Brian. Naturalizing Jurisprudence. pp. 168-169). 
para todo projeto investigativo ${ }^{64}$. Valores como simplicidade e coerência, no contexto da epistemologia, são propriedades que cada teoria pode ou não possuir ${ }^{65}$. Assim, é importante distinguir os valores adequados para decidir qual é a melhor proposição jurídica daqueles que indicam qual é a melhor concepção de direito.

Como Dworkin adota um procedimento para a obtenção de significado para termos valorativos, ele deve aceitar que isso valha também para os valores epistêmicos. Na teoria do direito, isso significa dizer que não existe um padrão para a formulação de modelos teóricos.

Uma teoria que não adote a perspectiva interna do participante não pode ser rejeitada de plano, somente pode ser suplantada por outra epistemologicamente melhor - em outras palavras, aquela que está mais de acordo com a melhor interpretação da prática da teoria do direito. Um positivismo inclusivo inicia com a vantagem de oferecer uma concepção de direito que explica uma quantidade maior de situações, pois não está vinculada a um ordenamento jurídico específico, de forma mais simples ${ }^{66}$.

Leiter entende que o interpretativismo deve competir de igual para igual com as teorias positivistas. Para ele, a concepção de direito de Dworkin está em franca desvantagem, justamente devido ao seu caráter local. O método interpretativo é uma escolha teórica baseada nas características de um sistema jurídico específico, o dos EUA.

64 Leiter menciona um exemplo apresentado por Julie Dickson, no qual um sujeito agnóstico narra uma missa católica. Ele precisa entender o que o ritual representa para os participantes. Para isso, ele deve ser capaz de julgar quais são seus elementos mais importantes, deve ter uma teoria sobre como uma boa missa deve ser celebrada. O sucesso de sua empreitada não tem relação com a sua religiosidade, ou falta dela (LEITER, Brian. Naturalizing Jurisprudence. p. 174).

65 PUTNAM, Hilary. Ethics Without Ontology. p. 69.

66 Não é a mesma coisa falar em elementos característicos de um conceito e falar em fenômenos abrangidos por uma teoria. Essa diferença é sutil e não será estudada aqui, mas é bem claro que, da perspectiva de Dworkin, análise conceitual e teoria do direito se confundem na ideia de interpretação da prática jurídica. Para Leiter, a diferença entre o significado (um conceito) e a melhor teoria disponível para explicar um dado objeto são coisas diferentes. $O$ que está sendo apresentada aqui é a ideia de que deve haver uma melhor explicação para o conceito de direito. Leiter argumenta também que é possível substituir a concepção de moralidade apresentada por Dworkin como visão ordinária por uma teoria científica. Neste caso, não há descrição do sentido de um conceito, mas de um fenômeno social e psicológico. Para uma discussão acerca das dificuldades do naturalismo moral. Cf. CABALLERO LOIS, Cecilia; ALMEIDA, Danilo. A Polêmica de Posner contra a Filosofia Moral: entre o realismo e o naturalismo. Jurispoiesis, Rio de Janeiro, a. 13, n. 13, p.1-2, 2011. 
Assim, um defeito importante desta teoria é que ela é demasiadamente "paroquial"; ele pode ser uma boa concepção do direito norte-americano, mas falha como tentativa de uma concepção geral do conceito de direito ${ }^{67}$. Deve ser possível formular uma concepção universal do direito, que, por não assumir a perspectiva interna que Dworkin adota, fixa seu significado por meio de um procedimento não interpretativo.

Segundo Leiter, Dworkin escreve como se o seu fosse o conceito de direito, mas a verdadeira questão, o que ele, Dworkin, deveria estar se esforçando em sustentar, é se o conceito de direito é o nosso conceito. Mas isso não retrata adequadamente a natureza da abordagem de Dworkin. Se este autor diz, nas palavras de Leiter, que o direito é a justificação da coerção estatal ${ }^{68}$ e que, portanto, a teoria do direito é a interpretação teleológica do corpo de práticas jurídicas; se é assim que ele retrata o procedimento do teórico do direito, então ele não precisa levar em conta aquilo que é aceito como o "nosso conceito de direito".

Dworkin pode sustentar que não é preciso haver um entendimento sobre os critérios de identificação do direito para que se possa conhecer seu propósito. 0 fato de não haver tais critérios compartilhados é irrelevante para a função do teórico do direito em sua concepção. De fato, ele sustenta que o pensamento jurídico demanda uma compreensão (understanting) das práticas jurídicas - seu sentido dentro da teia de valores que compõe a moralidade pública - e não explicações ${ }^{69}$.

A caracterização que Leiter faz da disputa é inadequada porque considera haver uma convergência de objetivos entre positivistas e interpretativistas. Como Dworkin deixa claro em seu último livro, seu conceito normativo de direito não pode ser entendido fora de uma teoria moral. Talvez Dworkin devesse ser interpretado como se dissesse que uma explicação neutra é inadequada não por ignorar a natureza ou o conceito que é efetivamente compartilhado, mas por rejeitar uma noção que deveria ser compartilhada, no sentido de ser mandatória do ponto de vista de sua doutrina moral ${ }^{70}$.

67 LEITER, Brian. Naturalizing Jurisprudence. p. 134.

68 LEITER, Brian. Naturalizing Jurisprudence. p. 165

69 DWORKIN, Ronald. Justice for Hedgehogs. p. 152.

70 Não é que não haja diferença entre o que é o direito e o que ele deveria ser. Significa apenas que descobrir quais são as demandas atuais do direito redunda em propor uma justifi- 
Seria como dizer que os juízes que afirmassem que o direito pode ser ao mesmo tempo válido e injusto estariam cometendo uma iniquidade. Talvez, para Dworkin, seja moralmente reprovável sustentar que o direito não tem um propósito, que ele não passa de mero instrumento do poder político. Se for esse mesmo o caso, talvez seja melhor largar o moralismo e tentar a sorte com uma abordagem mais realista e pessimista.

O diálogo entre as duas empreitadas, a do interpretativista e a do juspositivista, parece estar truncado. Cada um deles parece partir de lugares diferentes demais para que possa haver qualquer entendimento. Hart, em seu pós-escrito, parece ter entendido precisamente este ponto. Ele se mostra perplexo com a sugestão de que seu projeto e o de Dworkin, "tão diferentes" entre si, possam estar em conflito ${ }^{71}$.

De fato, talvez não estejam. Essa aparente contradição - duas concepções que se negam mutuamente, mas não estão em conflito - se parece com os exemplos de relatividade conceitual de Putnam. Como nesses casos, o dilema está na ambiguidade interpretativa de noções mais fundamentais que o que está sendo discutido.

Dworkin afirma que é impossível delimitar a fronteira e as relações entre direito e moral - um dos maiores problemas da filosofia do direito - sem assumir de início a resposta. Ou a questão é abordada desde um ponto de vista jurídico, de uma teoria das fontes do direito - que já deve adotar uma abordagem moralmente neutra, descritiva, da identificação e leitura dos textos jurídicos - ou de uma perspectiva moral, recorrendo a uma justificação para a separação - o que não passa de uma justificação das próprias instituições jurídicas ${ }^{72}$.

O positivista responderia que ele opera em outro nível, que tenta descrever como os participantes percebem a relação entre direito e moral. Isso não é nem jurídico, nem moral, mas conceitual.

Só resta a Dworkin recorrer a sua taxionomia dos conceitos ${ }^{73}$, que não passa de uma consequência direta da pressuposição de que juízos de fato são de uma

cação do uso da força pública em face da história institucional (DWORKIN, Ronald. Justice for Hedgehogs, pp. 407-408).

71 HART, Herbert. Pós-escrito. p. 311.

72 DWORKIN, Ronald. Justice for Hedgehogs. p. 403.

73 DWORKIN, Ronald. Justice for Hedgehogs. p. 404. 
natureza diferente dos juízos de valor. Pode-se concluir dizendo que, ainda que o conceito de direito possa ser normativo, não significa que ele deva sê-lo, da mesma forma que os teóricos do direito devem interpretar os argumentos uns dos outros segundo o princípio da caridade.

\section{CONSIDERAÇÕES FINAIS}

Otrabalho iniciou-se com a hipótese de que a noção de conceitos interpretativos defendida na obra de Dworkin não sustenta a sua conclusão sobre a incoerência do positivismo jurídico. Verificou-se que os juízos de valor permeiam todo tipo de investigação intelectual. Em especial, que ainda é possível justificar o positivismo, como tal, e não interpretado como convencionalismo, interpretativamente. Dworkin falha, por exemplo, ao não justificar sua teoria dos conceitos do ponto de vista de seus méritos epistêmicos.

Por isso, ele não pode concluir que a melhor abordagem para conceitos interpretativos, ou para qualquer conceito, é uma que separe entre investigações descritivas e valorativas. Uma abordagem integrada como a que o autor propõe deve ser justificada em termos de seus méritos epistêmicos, não apenas morais ou políticos.

Além disso, Dworkin não explica como deve ser uma teoria sobre conceitos criteriais mais complexos. Portanto, ele não está em posição de rejeitar a possibilidade de uma teoria positivista do direito. A melhor interpretação do conceito de direito pode indicar que ele, na verdade, é entendido como criterial.

Por isso, conclui-se aqui que o positivismo jurídico permanece como alternativa metodológica, pelo menos para um possível conceito de direito que não tenha algum sentido valorativo.

\section{REFERÊNCIAS}

CABALleRO LOIS, Cecilia; ALMEIDA, Danilo. A Polêmica de Posner contra a Filosofia Moral: entre o realismo e o naturalismo. Jurispoiesis, Revista do Curso de Direito da Universidade Estácio de Sá, Rio de Janeiro, a. 13, n. 13, p.1-2, 2011. 
DWORKIN, Ronad. Justice in Robes. Cambridge, EUA: Harvard U. Press, 2006.

- O Império do Direito. 2. ed. Tradução de Jefferson L. Camargo. São Paulo: Martins Fontes, 2007.

Justice for Hedgehogs. Cambridge, EUA: Harvard U. Press, 2011.

HART, Herbert. Pós-escrito. In:

O Conceito de Direito. Tradução de Antônio O. SetteCâmara. São Paulo: WMF Martins Fontes, 2009, p. 307-357.

LEITER, Brian. Naturalizing Jurisprudence: essays on American legal realism and naturalism in legal philosophy. Nova Iorque, EUA: Oxford U. Press, 2007.

PERRY, Stephen. Hart's Methodological Positivism. In. COLEMAN, Jules (ed.) Hart's Postscript: essays on the Postscript to the Concept of Law. Nova Iorque, EUA: Oxford U. Press, 2001, p. 311-354.

PUTNAM, Hilary. Reason, Truth, and History. Nova Iorque, EUA: Oxford U. Press. 1981.

. The Many Faces of Realism: the Paul Carus lectures. Lasalle, EUA: Open Court, 1987.

Realism with a Human Face. Cambridge, EUA: Harvard U. Press, 1990.

. Pragmatism and Moral Objectivity. In: Words and Life. Cambridge, EUA: Harvard U. Press, 1994, p. 151-181.

. Ethics Without Ontology. Cambridge, EUA: Harvard University Press, 2004.

. O Colapso da Verdade e Outros Ensaios. Tradução de Pablo R. Mariconda e Sylvia G. Garcia. Aparecida: Idéias \& Letras, 2008.

RAZ, Joseph. Two Views of the Nature of the Theory of Law: a partial comparison. In. COLEMAN, Jules (ed.) Hart's Postscript: essays on the Postscript to the Concept of Law. Nova Iorque, EUA: Oxford U. Press, 2001, p. 1-37.

SOLUM, Lawrence, The Unity of Interpretation, Boston University Law Review, v. 90, n. 2, pp. 551-578, abr. 2010.

STAVROPOULOS, Nicos. Interpretivist Theories of Law. In: VILLANUEVA, Enrique (org.). Law: metaphysics, meaning and objectivity. Nova Iorque, EUA: Rodopi, 2007. 